\title{
The surprisingly high ligation energy of CO to Ruthenium porphyrins
}

Niloufar Shafizadeh, Séverine Boyé-Péronne and Satchin Soorkia.

Institut des Sciences Moléculaires d'Orsay (ISMO), CNRS, Université Paris-Saclay, Université Paris-Sud, Orsay F91405, France.

Barbara K. Cunha de Miranda, Gustavo A. Garcia and Laurent Nahon.

Synchrotron SOLEIL, L'orme des Merisiers, Saint-Aubin - BP 48 - 91192 Gif-sur-Yvette Cedex, France.

Shufeng Chen ${ }^{1,}$ Aurélien de la Lande.

Laboratoire de Chimie Physique, CNRS, Université Paris-Sud, Université Paris Saclay, Orsay F-91405, France.

1-present address School of Chemical and Environmental Engineering, Shanghai Institute of Technology, Shanghai 201418, People's Republic of China

Lionel Poisson and Benoît Soep.

LIDYL, CEA, CNRS, Université Paris-Saclay, CEA Saclay 91191 Gif-sur-Yvette France.

\section{Abstract}

A combined theoretical and experimental approach has been used to investigate the binding energy of a ruthenium metalloporphyrin ligated with $\mathrm{CO}$, ruthenium tetraphenyl porphyrin $\left[R u^{\text {II }}\right.$ TPP $]$ in the $\mathrm{Ru}^{\mathrm{II}}$ oxidation degree. Measurements made by VUV ionization with the DESIRS beamline at Synchrotron SOLEIL lead to adiabatic ionization energies of $\left[R u^{I I} T P P\right]$ and its complex with $\mathrm{CO},\left[\mathrm{Ru}^{\mathrm{II}} \mathrm{TPP}-\mathrm{CO}\right]$, to be $6.48 \pm 0.03 \mathrm{eV}$ and $6.60 \pm 0.03 \mathrm{eV}$, respectively while the ion dissociation threshold of $\left[\mathrm{Ru}^{\mathrm{II}} \mathrm{TPP}-\mathrm{CO}\right]^{+}$is measured at $8.36 \pm 0.03 \mathrm{eV}$. These experimental data are used to derive binding energies of the $\mathrm{CO}$ ligand in the neutral and cationic complex (1.88 $\pm 0.06 \mathrm{eV}$ and $1.76 \pm 0.06 \mathrm{eV}$, respectively) using a Born-Haber cycle. Density Functional Theory calculations, in very satisfactory agreement with the experimental results, help to get insights into the metal-ligand bond. Notably, the high ligation energies can be rationalized in terms of the ruthenium orbital structure, which is singular from that of the iron atom. Thus, beyond indications of a strengthening of the Ru-CO bond from the decrease in the $\mathrm{CO}$ vibrational frequency in the complex as compared to the $\mathrm{Fe}-\mathrm{CO}$ bond, high level calculations are essential to describe accurately the metal ligand ( $\mathrm{CO}$ ) bond and show that the Ru-CO bond energy is strongly affected by the splitting of triplet and singlet spin states in uncomplexed [Ru TPP]. 


\section{Introduction}

The binding equilibrium of small molecules to hemoproteins determines the activation of many vital functions, effective through the streaming of the ligated molecules in the blood of living systems to the functional targets. However, the experimental determination of fundamental properties such as the binding energies of ligands to the active molecular center of hemoproteins, a metalloporphyrin, is not straightforward and hampered by many constraints, such as the indirect character of the measurements. Equally, in quantum mechanical modeling there are major difficulties when dealing with the size of the porphyrins and the complex electronic structure of the core transition metal in the cavity. As an example, for ruthenium II porphyrins, it is difficult to predict the spin multiplicity, i.e. singlet, triplet or quintet, of the lowest energy states. This is an essential property since there is a spin cross over between the ligated and unligated metalloporphyrin ${ }^{1}$. Therefore, a stringent benchmarking approach is needed whereby state-of-theart calculations are confronted with advanced and direct measurements on the very same molecular systems.

Most of the measurements on the binding energy of ligated porphyrins are equilibrium constant measurements that allow a comparison of the affinity of a given hemoprotein for a ligand ${ }^{2}$. One can thereby derive from the free enthalpy $(\Delta \mathrm{G})$, the enthalpy change $(\Delta \mathrm{H})$ after evaluation of the entropy change $\Delta \mathrm{S}: \Delta \mathrm{H}=\Delta \mathrm{G}+\mathrm{T} \Delta \mathrm{S}$, where $\mathrm{T}$ is the absolute temperature. This latter evaluation of $\Delta \mathrm{S}$ is approximate and relies on comparisons with known systems or calculations. The van $\mathrm{t}^{\prime}$ Hoff relation, which gives the relationship between the temperature and the equilibrium constant, allows a direct access to $\Delta \mathrm{H}$. However, investigating the temperature dependence for such compounds is challenging. Extrapolation of $\Delta \mathrm{H}$ to $\mathrm{T}=0 \mathrm{~K}$ has to be made to compare with the difference of potential energies $\Delta \mathrm{E}$ obtained from quantum calculations. Therefore, a more direct type of measurements of the energy at temperatures closer to $0 \mathrm{~K}$ is required.

In addition, binding energy measurements allow to quantify the influence of the binding metal electronic structure onto the ligand. Besides studying iron porphyrins ${ }^{3}$, it is important to investigate equivalent electronic structures, for instance using the ruthenium atom as the center 
atom in the metalloporphyrin. This atom is below Fe, in the same column of the Mendeleev table, with the same number of valence electrons.

In this paper, we present a, alternative experimental approach, where the binding energy of the ligand to the metalloporphyrin (see Figure 1) is measured quasi directly in the gas phase through the assignment of the adiabatic ionization and the appearance energy of the complex dissociation. The $\mathrm{CO}$ molecule is ligated to the ruthenium atom of the metalloporphyrin (as shown by crystallography) along the normal $\sigma$ bond of $\mathrm{CO}$ with transition metals ${ }^{4}$. This complex was selected for its similarity to ligated iron porphyrins that show a much stronger affinity to $\mathrm{CO}$ than $\mathrm{O}_{2}$, which explains carbon monoxide poisoning in living systems using hemoproteins for transport and storage of dioxygen.

Furthermore, each of these binding and ionization energies has been calculated by density functional methods (DFT) and separately compared with the experimental results. Since the binding energies are determined in a solvent-free environment and at a temperature close to $0 \mathrm{~K}$, a straightforward comparison with quantum chemistry calculations is possible. A surprisingly high binding energy (in the order of $\sim 2 \mathrm{eV}$ ) has been found, more than twice that of the equivalent iron metalloporphyrin ${ }^{5}$ in the same column of the Mendeleev table. This will be discussed in terms of the specific interaction of the $\mathrm{Ru}^{\mathrm{II}}(4 \mathrm{~d})$ orbitals with $\mathrm{CO}\left(\pi^{*}\right)$ orbitals as compared with that of $\mathrm{Fe}^{\mathrm{II}}(3 \mathrm{~d})$ with $\mathrm{CO}\left(\pi^{*}\right)$.

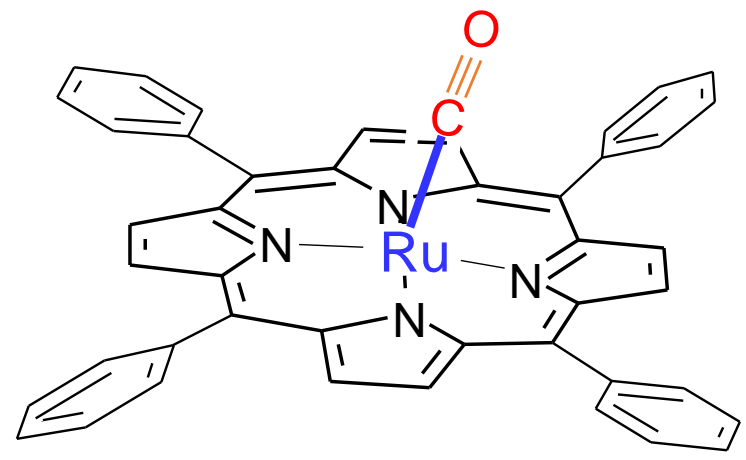

Figure 1: Scheme of ruthenium tetraphenyl porphyrin [Ru $\left.{ }^{I I} \mathrm{TPP}-\mathrm{CO}\right] \mathrm{C}_{44} \mathrm{H}_{28} \mathrm{~N}_{4} \mathrm{Ru}-\mathrm{CO}$. 


\section{Experimental methodology}

\section{Principle}

The binding energies are deduced from a Born-Haber cycle ${ }^{6}$ shown in Figure 2. It relies on three experimental determinations: (i) the adiabatic ionization energy ( $\left.\mathrm{IE}_{[\mathrm{Ru} \text { TPP-CO]}}\right)$ of [Ru TPP-CO], (ii) the adiabatic ionization energy ( $\left.\mathrm{IE}_{[\mathrm{Ru} T P P}\right)$ of $[\mathrm{Ru} \mathrm{TPP}]$, and (iii) the dissociation energy $\left(\mathrm{E}_{\mathrm{Diss}[\mathrm{Ru}} \mathrm{TPP}-\mathrm{CO}^{+}\right)$of $[\mathrm{Ru} \mathrm{TPP}-\mathrm{CO}]^{+}$into $[\mathrm{Ru} \mathrm{TPP}]^{+}$and $\mathrm{CO}$. As can be seen in Figure 2, the ligation energies of $\mathrm{Ru}$ to $\mathrm{CO}$ in both the neutral and cationic complexes are directly derived. The

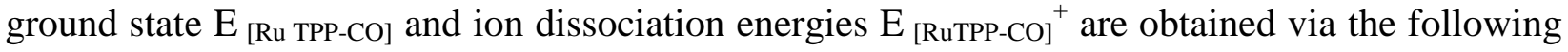
equations (see Figure 2)

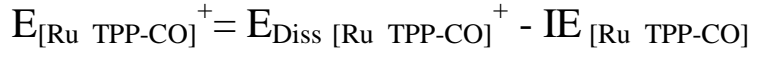

$\mathrm{E}_{[\mathrm{Ru} \text { TPP-CO }]}=\mathrm{E}_{\text {Diss[Ru TPP-CO }}^{+}-\mathrm{IE}_{[\mathrm{Ru} \text { TPP }]}=\mathrm{IE}_{[\mathrm{Ru} \text { TPP-CO }]}+\mathrm{E}_{[\mathrm{Ru} \text { TPP-CO }]}^{+}-\mathrm{IE}_{[\mathrm{Ru} T P P]}$

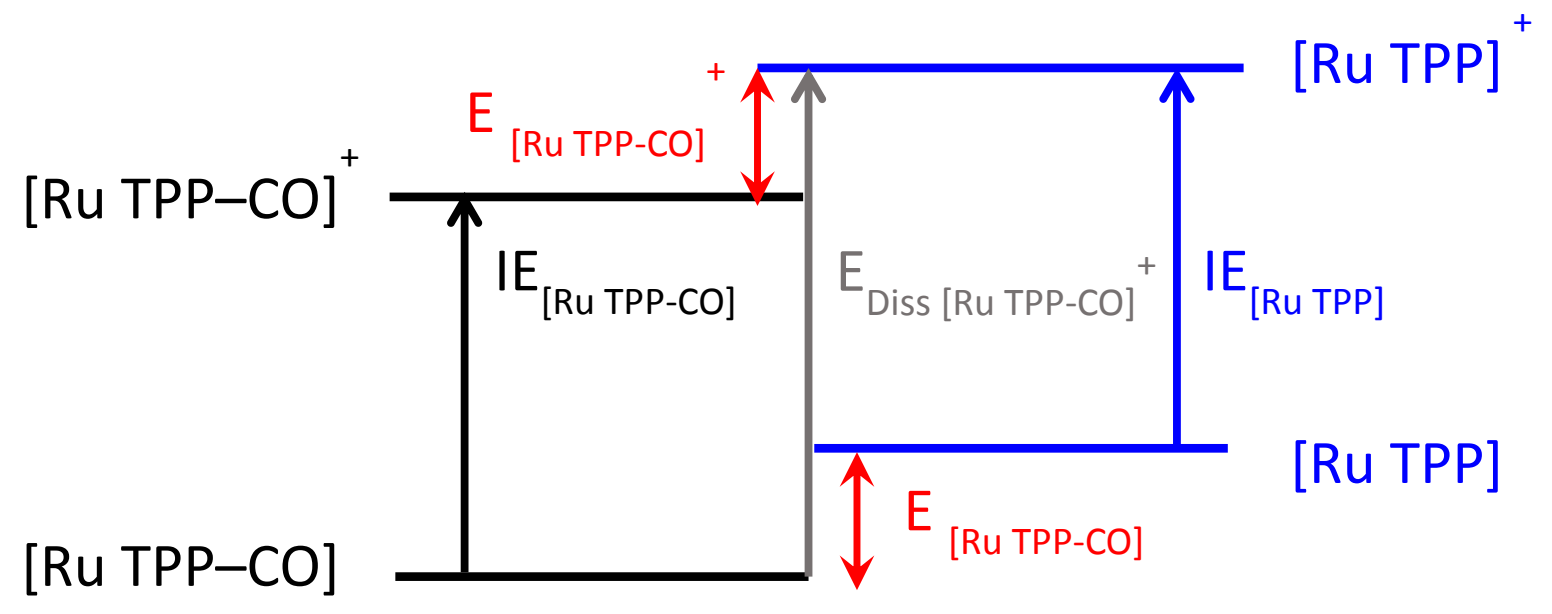

Figure 2: Born-Haber cycle through the ionization of [Ru TPP-CO] and [Ru TPP].

The dissociation and ionization threshold measurements were performed using the SAPHIRS molecular beam setup ${ }^{7,8}$ equipped with the DELICIOUS III spectrometer ${ }^{9}$ permanently installed on the DESIRS beamline ${ }^{10}$ at the SOLEIL French synchrotron facility. As previously described, 
the linearly polarized VUV-light generated by the undulator is first filtered through a gas cell flowed with argon to remove the $\mathrm{n}>1$ harmonics ${ }^{11}$ before entering a $6.65 \mathrm{~m}$-long monochromator equipped here with a low resolution/high flux 200 grooves/mm grating, set to provide an energy resolution in the range $4-17 \mathrm{meV}$ between 6 and $12 \mathrm{eV}$ photon energy, here $7.5 \mathrm{meV}$.

[Ru TPP-CO] (Sigma Aldrich) placed in a temperature-controlled oven, is heated to $300-600{ }^{\circ} \mathrm{C}$ and seeded in Helium/Neon/Argon carrier gases at 1.1 bar. A continuous supersonic expansion through a $30 \mu \mathrm{m}$ diameter nozzle generates a cold free jet. The latter is doubly-skimmed, and the resulting molecular beam crosses the synchrotron beam at a right angle in the ionization chamber. Neon is the preferred gas used for its increased collision efficiency compared to helium, achieving a $\sim 30 \mathrm{~K}$ rotational cooling while being transparent in the present energy range.

For oven temperatures below $500{ }^{\circ} \mathrm{C}$ (a measured indication value), [Ru TPP-CO] is found to be evaporated intact while above this value, thermal dissociation of the CO ligand is observed. Thus, by adjusting the oven temperature, it is possible to have both species, i.e. [Ru TPP] and [Ru TPP-CO], present simultaneously in the molecular beam. This allows via electron/ion coincidence, the determination of the ionization energies of both ligated and unligated complexes in the same experiment using only [Ru TPP-CO] in the oven.

The photoelectrons and photoions formed at the center of the spectrometer were accelerated in opposite directions by a $88 \mathrm{~V} / \mathrm{cm}^{-1}$ field and analyzed in coincidence by a velocity map imager ${ }^{12}$ and a momentum imager respectively. The coincidence scheme yields photoelectron images that can be filtered in ion mass and kinetic energy. At each photon energy, the corresponding massselected photoelectron spectra are extracted from these images after applying the pBASEX $\operatorname{method}^{13}$. Thus, the photoelectron signal is obtained as a function of both the photon energy and the electron kinetic energy, I(hv, eKE). This $2 \mathrm{D}$ matrix can be reduced into different $1 \mathrm{D}$ projections, one of which, the slow photoelectron spectroscopy (SPES) ${ }^{14-16}$, has been used here to measure the ionization spectroscopy of the RuTPP complexes. The commonly used threshold photoelectron spectroscopy (TPES) sums only over $e K E_{\max }$, the threshold electrons, $I^{T P E S}(h v)=$ $\int_{0}^{e K E_{\max }} I(h v, e K E) d e K E$. In contrast, SPES offers a more convenient trade-off between signalto-noise and resolution since it integrates along the lines of constant slopes of the photoelectron 
spectrum as a function of the synchrotron energy hv. These lines correspond to the direct ionization processes: $I^{S P E S}(h v)=\int_{0}^{e K E_{\max }} I(h v+e K E, e K E) d e K E$, where $e K E_{\max }$ can now generally be $4-5$ times larger than for TPES for the same final resolution. In this particular case, we chose a $e K E_{\max }$ value of $0.4 \mathrm{eV}$, yielding a resolution of $30 \mathrm{meV}$.

\section{Experimental results}

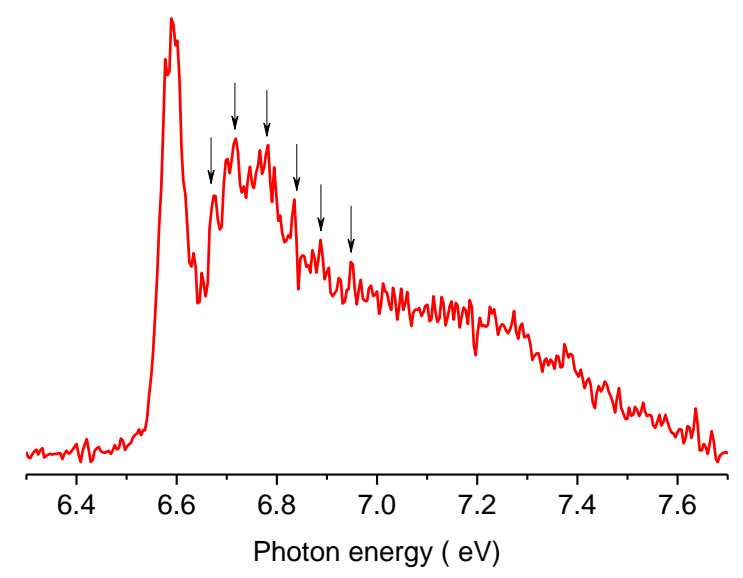

Figure 3 -SPES spectrum of [Ru TPP-CO] in the 6.3 to $7.7 \mathrm{eV}$ synchrotron photon energy range, with scan steps of $6 \mathrm{meV}$ and an overall resolution of $30 \mathrm{meV}$. The arrows indicate vibrational structures in the ion (see text).

In Figure 3, the SPES spectrum of [Ru TPP-CO] in the 6.3 to $7.7 \mathrm{eV}$ range was obtained in coincidence with the mass of the parent, which is unambiguously characterized by its mass spectrum (shown in Figure 1 of the ESI ) with the isotopic distribution of masses characteristic of ruthenium porphyrin isotopomers.

The spectrum rises sharply to a narrow peak with maximum at $6.59 \mathrm{eV}$. Taking into account the Stark shift $(7 \mathrm{meV})$ of the ionization potential in the ionization region of the instrument, the ionization potential is measured to be $(6.60 \pm 0.03) \mathrm{eV}$. After this maximum, a series of reproducible peaks at $6.68,6.72,6.78,6.84$ and $6.88 \mathrm{eV}$ is observed corresponding to a $40 \mathrm{meV}$ 
progression. The very weak low energy tail below the threshold at $6.55 \mathrm{eV}$ can be ascribed to a hot band progression of low frequency modes. Indeed, its ratio to the peak maximum varies with the source temperature. Fitting an exponential form e(-E/kT) yields a vibrational temperature of $\approx 170 \mathrm{~K}$. This corresponds to a minor contribution of incompletely vibrationally cooled [Ru TPP$\mathrm{CO}]$ molecules in the ionization region.

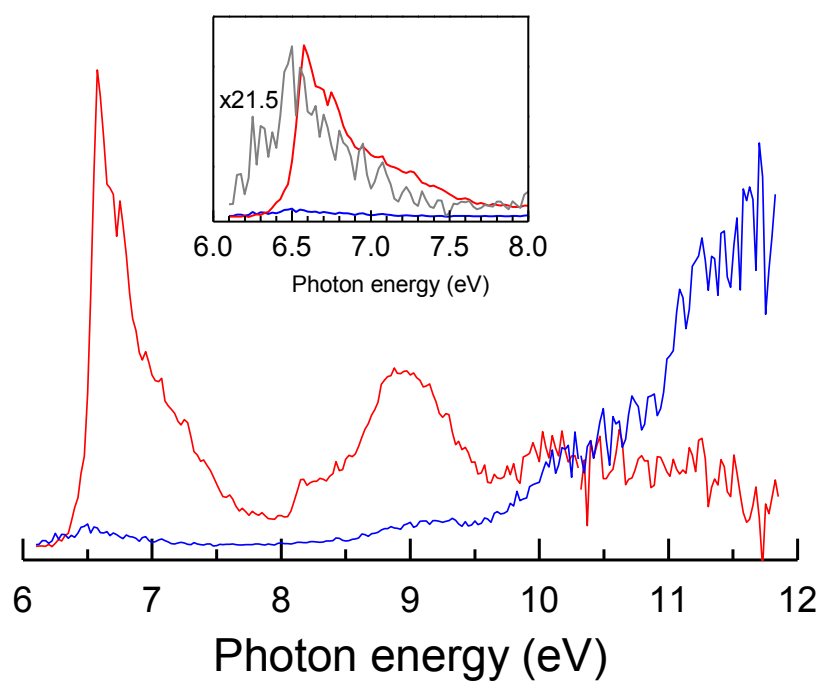

Figure 4: SPES spectrum of [Ru TPP-CO] (red trace) and [Ru TPP] (blue trace) between 6 and $12 \mathrm{eV}$ with a resolution of $30 \mathrm{meV}$. The insert shows the comparison of the signal of [Ru TPP-CO] (red trace) and a blowup of the signal of [Ru TPP] by a factor of 21.5 (grey trace). One observes that the grey trace is red shifted by $0.12 \mathrm{eV}$ from the red curve.

When the oven is heated above $500{ }^{\circ} \mathrm{C}$, thermally deligated [ $\left.\mathrm{Ru}{ }^{\mathrm{II}} \mathrm{TPP}\right]$ molecules are also detected in small amounts along with [Ru TPP-CO]. Figure 4 shows the SPES spectrum of [Ru TPP-CO] in red together with that of $[\mathrm{Ru}$ TPP] in blue. The grey trace in the insert is the $[\mathrm{Ru}$ TPP] signal multiplied by a factor of 21.5. Assuming that the ionization cross sections are identical and correspond to ionization of the macrocycle, this factor indicates a concentration ratio of $(1 / 21.5)$ for $[\mathrm{Ru} \mathrm{TPP}] /[\mathrm{Ru}$ TPP-CO]. It is to be noted that a shift of $0.12 \mathrm{eV}$ between the two maxima is observed in the inset of Figure 4. The ionization potential of [Ru TPP] can in the same manner as for the ligated species be obtained as $(6.48 \pm 0.03) \mathrm{eV}$ with this low energy shift. 
The overall shape of the SPES spectrum is the same for both species from the onsets of the signals up to around $8.5 \mathrm{eV}$. 


\section{CO dissociation threshold for [Ru TPP-CO $]^{+}$}

Monitoring the ion/electron coincidence spectra at the mass of [Ru TPP] yields interesting results. At low photon energies, just above $6 \mathrm{eV}$, the signal at $\mathrm{m} / \mathrm{z} 714$ corresponds to ionization of $[\mathrm{Ru}$ TPP] originating from thermal dissociation in the oven, as already mentioned. As can be seen in Figure 4 (blue trace), a second onset is observed $\sim 8.4 \mathrm{eV}$ while the [Ru TPP] ion yield keeps increasing with increasing photon energy. This corresponds to the dissociation of $[\mathrm{Ru}$ $\mathrm{TPP}_{-\mathrm{CO}}{ }^{+}$along the Ru-CO coordinate. In the best signal conditions to detect the photodissociation threshold, a contribution of the thermal dissociation is observed and easily characterized at the ionization threshold. In order to obtain the pure photodissociative ionization signal and assuming that the ionization cross sections are the same for [Ru TPP] and [Ru TPP$\mathrm{CO}$ ] but shifted by $0.12 \mathrm{eV}$, the thermal contribution was substracted from the total [Ru TPP] signal by using the scaled (1/21.5) and shifted [Ru TPP-CO] curve from Figure 4, yielding the RuTPP corrected ion intensity. The photodissociation yield $\mathrm{Y}$ is derived from the equation below and plotted in Figure 5.

$$
Y=\frac{\text { RuTPP corrected Ion intensity }}{(\text { RuTPPCO ion intensity }+ \text { RuTPP corrected Ion intensity })}
$$

Figure 5 shows the evolution of the dissociation yield $\mathrm{Y}$ of $[\mathrm{Ru} \text { TPP-CO }]^{+}$, as a function of the synchrotron photon energy. By linear extrapolation of the dissociation curve through the appearance of $[\mathrm{Ru} \mathrm{TPP}]^{+}$, a limit of $\mathrm{E}_{\text {Diss [Ru TPP-CO }{ }^{+}}=8.36 \pm 0.03 \mathrm{eV}$ is found after Stark shift correction. This value assumes a fast dissociation (no kinetic shifts), no barrier and no internal excitation of the fragment products. The first two assumptions will be confirmed further down the text. This results in an ion dissociation energy $\mathrm{E}_{\left[\mathrm{Ru} \text { TPP-CO }{ }^{+}=1.76 \pm 0.06 \mathrm{eV}(8.36-6.60)\right.}$ and $\mathrm{E}_{[\text {Ru TPP-CO] }}=1.88 \pm 0.06 \mathrm{eV}(8.36-6.48)$ for the neutral species (see Figure 2). 


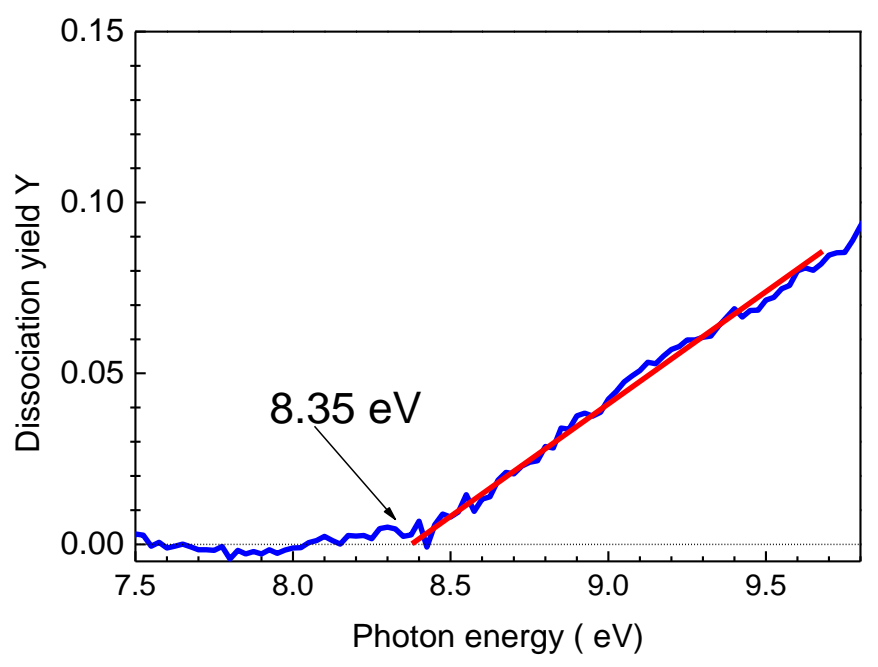

Figure 5: Dissociation yield of $[\mathrm{Ru} \mathrm{TPP}-\mathrm{CO}]^{+}$in the 7 to $9.8 \mathrm{eV}$ photon energy range. The red line indicates a linear extrapolation of the signal to extract the onset of photodissociation, indicated by an arrow at $8.35 \mathrm{eV}$.

\section{Computational Details}

We have investigated the mechanism of photodissociation of the Ru-CO bond in [Ru TPP-CO] by means of Density Functional Theory (DFT) ${ }^{17}$, as implemented in Gaussian $09{ }^{18}$. We used the 6-311 $\mathrm{g} * *$ basis set on $\mathrm{C}, \mathrm{H}$ and $\mathrm{O}$ atoms, the 6-311+g** basis set on the $\mathrm{N}$ atom which includes diffuse atomic orbitals, ${ }^{19}$ and the SDD basis set, associated with relativistic effects described by Stuttgart/Dresden effective core potentials $(\mathrm{ECPs})^{20}$, on the Ru atom. Equilibrium geometries of [Ru TPP $]$ (singlet and triplet states), and of $[\mathrm{RuTPP}]^{+}$(doublet and quartet) were sought by geometry optimization without any symmetry constraints. We used the B3LYP ${ }^{21}, \mathrm{M} 06-\mathrm{L}^{22,23}$ and M11 ${ }^{24}$ functionals. B3LYP is a global hybrid functional, M06L is a meta-GGA functional and M11 is a range-separated meta-GGA functional. These functionals including various percentages of exact exchange were chosen because of the link between the porphyrin ring and the partially conjugated phenyl groups. Vibrational frequencies were calculated to ensure the local minimum 
character of the optimized structures. For the five-coordinate CO-ligated ruthenium porphyrin, the singlet state has been indicated to be the ground state. ${ }^{25}$ The four-coordinate ruthenium ${ }^{\text {II }}$ porphyrin usually forms as a dimer via a $\mathrm{Ru}=\mathrm{Ru}$ bond ${ }^{26}$, thus the ground state of the unligated ruthenium porphyrin monomer is still unknown, to our knowledge. Therefore, first the ground state properties of CO-free ruthenium tetraphenylporphyrin $[\mathrm{Ru} T P P]$ and its cation $[\mathrm{Ru} T P P]^{+}$ have been determined. Our calculations showed that the triplet state and the quartet state are the ground states of respectively $[\mathrm{Ru} \mathrm{TPP}]$ and $[\mathrm{Ru} \mathrm{TPP}]^{+}$. Population analysis, ionization energy (IE) of neutral molecules, electron affinity (EA) of ion complexes were calculated. Regarding the dissociation curves of the low-lying states of [Ru TPP-CO], the dissociation coordinate (Ru-CO bond stretch coordinate) was constructed in the $\mathrm{S}_{0}$ state. It was shown that the equilibrium structure of the porphyrins is not sensitive to the $\mathrm{XC}$ (exchange) functional ${ }^{27}$, which is also the case in our calculations. We successively increased the Ru-CO bond length from 1.8 to $5.0 \AA$, carrying out constrained geometry optimizations at each point. That is, for a given Ru-C distance ranging from 1.8 to $5.0 \AA$, all the remaining degrees of freedom were relaxed during optimizations. The range-separated CAM-B3LYP ${ }^{28}$ functional was then employed to calculate the vertical excitation energies of the lowest thirty excited states. CAM-B3LYP is expected to treat with sufficient accuracy both the charge-transfer states and the local valence excitations involved in the photodissociation pathway of neutral [Ru TPP-CO].

\section{Theoretical results}

Spin states of [Ru TPP]

All three functionals show that the ground state of free [Ru TPP] is a triplet state as for the corresponding free Fe porphyrin ${ }_{2}^{29}{ }_{2}^{30}$ and the ground state of $[\mathrm{Ru} \mathrm{TPP}]^{+}$is quartet state (

Table 1). The energy difference between the ground triplet state and the low-lying singlet for $[\mathrm{Ru}$ TPP], and that of the doublet with the quartet state, for $[\mathrm{Ru} \mathrm{TPP}]^{+}$, are sufficiently large to discard an artifact of DFT in predicting the lowest spin states. On the other hand, the energy difference between respectively singlet and triplet, or doublet and quartet states is strongly 
dependent on the $\mathrm{XC}$ (exchange functional) so that a definite estimate of the absolute energy splitting between the different spin states is not possible.

Table 1 : Calculated relative energies $(\mathrm{eV})$ of $[R u T P P]$ and $[R u T P P]^{+}$.

\begin{tabular}{ccccc}
\hline & spin state & B3LYP & M06L & M11 \\
\hline$[\mathrm{Ru} \mathrm{TPP}]$ & singlet & 0.87 & 1.13 & 0.63 \\
& triplet & 0.00 & 0.00 & 0.00 \\
{$[\mathrm{Ru} \mathrm{TPP}]^{+}$} & doublet & 1.48 & 0.82 & 0.95 \\
& quartet & 0.00 & 0.00 & 0.00 \\
\hline
\end{tabular}

In Table 2 , the geometries of [Ru TPP] and [Ru TPP ${ }^{+}$optimized with B3LYP, M06L and M11 functionals show very similar Ru-N bond lengths for every electronic configuration, except for the quartet state of $\left[\begin{array}{ll}R u & T P P\end{array}\right]^{+}$. For this state, the optimized Ru-N bond with B3LYP and M06L are similar (2.036 and 2.039 ̊), but M11 gave a longer distance (2.070 ̊). The Ru-N distance of $\left[\begin{array}{ll}R u & T P P\end{array}\right]$ in the singlet state is shorter than that of $\left[\begin{array}{lll}R u & T P P\end{array}\right]^{+}$ground doublet state. On the contrary the Ru-N bond length of $\left[\mathrm{Ru}\right.$ TPP] in the triplet state is longer than that of $[\mathrm{Ru} T P P]^{+}$in the quartet state. The dihedral angles between the phenyl and porphyrin rings when optimized with B3LYP functionals are always larger than the corresponding ones with M06L and M11 functionals. The optimum dihedral angles result from a subtle balance between steric hindrance and electron delocalization between the phenyl and porphyrin rings. This competition and consequently the optimal angle are known to be strongly dependent on the $\mathrm{XC}$ functional (see e.g. ${ }^{32,33}$ ). Also, the corresponding results for $[\mathrm{Ru}$ TPP-CO $]$ and $[\mathrm{Ru} \text { TPP-CO }]^{+}$are similar to those for $\left[\mathrm{Ru}\right.$ TPP] and $[\mathrm{Ru} \mathrm{TPP}]^{+}$. Ru-CO is linear in CO-ligated complexes, and the Ru atom remains within the plane of the porphyrin ring for all molecules. 
Table 2 : Geometrical structure of uncomplexed, complexed and ionic [Ru TPP] porphyrins. The main bond lengths $(\AA)$ and dihedral angles $\left(^{\circ}\right)$ of the optimized structures.

\begin{tabular}{|c|c|c|c|c|c|}
\hline & & & B3LYP & M06L & M11 \\
\hline \multirow[t]{4}{*}[\mathrm{Ru}\mathrm{TPP}]{} & singlet & $\mathrm{R}(\mathrm{Ru}-\mathrm{N})$ & 2.034 & 2.031 & 2.061 \\
\hline & & $\alpha_{\text {phenyl }}$ & 80 & 64 & 66 \\
\hline & triplet & $\mathrm{R}(\mathrm{Ru}-\mathrm{N})$ & 2.055 & 2.058 & 2.061 \\
\hline & & $\alpha_{\text {phenyl }}$ & 78 & 63 & 67 \\
\hline \multirow[t]{4}{*}[\begin{array}{ll}{\mathrm{Ru}}&{\mathrm{TPP}}\end{array}]{$^{+}$} & doublet & $\mathrm{R}(\mathrm{Ru}-\mathrm{N})$ & 2.071 & 2.052 & 2.071 \\
\hline & & $\alpha_{\text {phenyl }}$ & 65 & 59 & 63 \\
\hline & quartet & $\mathrm{R}(\mathrm{Ru}-\mathrm{N})$ & 2.036 & 2.039 & 2.070 \\
\hline & & $\alpha_{\text {phenyl }}$ & 78 & 63 & 63 \\
\hline \multirow[t]{3}{*}{ [Ru TPP-CO] } & singlet & $\mathrm{R}(\mathrm{Ru}-\mathrm{N})$ & 2.067 & 2.068 & 2.063 \\
\hline & & $\mathrm{R}(\mathrm{Ru}-\mathrm{CO})$ & 1.791 & 1.780 & 1.782 \\
\hline & & $\alpha_{\text {phenyl }}$ & 90 & 64 & 67 \\
\hline \multirow{3}{*}{$\underset{\mathrm{CO}^{+}}{[\mathrm{Ru} \text { TPP- }}$} & doublet & $\mathrm{R}(\mathrm{Ru}-\mathrm{N})$ & 2.075 & 2.073 & 2.073 \\
\hline & & $\mathrm{R}(\mathrm{Ru}-\mathrm{CO})$ & 1.798 & 1.785 & 1.795 \\
\hline & & $\alpha_{\text {phenyl }}$ & 65 & 58 & 63 \\
\hline
\end{tabular}

Calculations and experimental results on ionization potentials and dissociation energies are summarized in Table 3. The calculations yield ionization potentials that are in average within the $6.5 \mathrm{eV}$ domain, commonplace for porphyrins ${ }^{34,35,36}$. 
Table 3: Ionization and binding energies with CO for [Ru TPP]. The calculated vertical ionization potential (IP) and electron affinity (EA). Calculated binding energy of CO ligand without or with (in brackets) zero-point correction and BSSE. Energies are in $\mathrm{eV}$.

\begin{tabular}{cccccc}
\hline & & B3LYP & M06L & M11 & exp \\
\hline$[\mathrm{Ru} \mathrm{TPP}]$ & IE & 6.06 & 6.12 & 6.70 & $6.48 \pm 0.03$ \\
{$[\mathrm{Ru} \mathrm{TPP}]^{+}$} & EA & 5.89 & 5.99 & 6.04 & \\
{$[\mathrm{Ru} \mathrm{TPP-CO}]$} & IE & 6.58 & 6.35 & 6.64 & $6.60 \pm 0.03$ \\
& binding & $2.14(1.93)$ & $2.17(1.97)$ & $2.21(1.97)$ & $1.88 \pm 0.06$ \\
{$[\mathrm{Ru} \mathrm{TPP-CO}]^{+}$} & energy & & & & \\
& EA & 6.34 & 6.23 & 6.48 & \\
& & & & & \\
& binding & $1.69(1.50)$ & $1.93(1.71)$ & $1.77(1.53)$ & $1.76 \pm 0.06$ \\
\hline
\end{tabular}

The average of the calculated values is $6.29 \mathrm{eV}$ for [ $\left.\mathrm{Ru}^{\mathrm{II}} \mathrm{TPP}\right]$ and $6.5 \mathrm{eV}$ for [Ru TPP-CO]. There is some dispersion of the values with the functionals, however after correction for zero point energy and basis set superposition errors (BSSE), the calculated binding energy of Ru-CO in neutral species is very close to $1.88 \mathrm{eV}$, while the corresponding values for ionic species $[\mathrm{Ru}$ TPP-CO $]^{+}$are more different with an average of $1.58 \mathrm{eV}(1.76 \mathrm{exp})$. The result, aside from calculation differences characterizes a high ligand binding energy for both neutral and ionic porphyrins. The calculated Ru-CO binding energy is lower in the ion, as the experimentallyderived values. This most likely stems from spin state energy differences in neutral and ionic complexes, as we shall see in the discussion. 
Harmonic frequencies of [Ru TPP-CO]

Table 4 Calculated Harmonic frequencies for $\mathrm{C}-\mathrm{O}$ and $\mathrm{Ru}-\mathrm{CO}$ stretching modes $\left(\mathrm{cm}^{-1}\right.$ and between brackets with the scaling factor 0.96), compared with the experimental values.

\begin{tabular}{ccc}
\hline Theory & $v(\mathrm{C}-\mathrm{O})$ & $v_{\text {stretch }}(\mathrm{Ru}-\mathrm{CO})$ \\
\hline B3LYP & $2019(1938)$ & 582 \\
M06L & $2016(1935)$ & 584 \\
M11 & $2096(2012)$ & 578 \\
\hline Exp. & \\
\hline
\end{tabular}

$\begin{array}{cc}\text { RuTPP-CO in Argon matrices } & 1951^{\text {a }} \\ \text { Ru-CO in neon matrices } & 2085^{\mathrm{b}} \\ \text { Ru TPP-CO-Pyridine in } \mathrm{CH}_{2} \mathrm{Cl}_{2} & 1943^{\mathrm{c}} \\ \text { Fe TPP CO Pyridine in } \mathrm{CH}_{2} \mathrm{Cl}_{2} & 1975^{\mathrm{c}}\end{array}$

Free $\mathrm{CO}$ in argon matrix $2150^{\mathrm{d}}$

\footnotetext{
a- Values from ref. ${ }^{37}$

b- $\mathrm{CO}$ in Ru-CO in neon matrices in absence of porphyrins ref. ${ }^{38}$

c- Value from ref ${ }^{39}$

d- Values from ref $^{40}$.
}

We calculated the harmonic frequencies for [Ru TPP-CO] and we present the $\mathrm{CO}$ stretching mode and the Ru-CO bond frequencies in Table 4 . The frequencies computed for the $\mathrm{CO}$ stretch with B3LYP or M06L agree well with the experimental value of $1951 \mathrm{~cm}^{-137}$ after application of the widely accepted 0.96 scaling factor. ${ }^{41}$ M11 functionals yield slightly larger values. As expected, the $\mathrm{CO}$ bond stretch frequency for bound [Ru TPP-CO] is lower by $199 \mathrm{~cm}^{-1}$ from that 
of free $\mathrm{CO}$ in argon matrices. Observation of $\mathrm{CO}$ bound to a single ruthenium atom in a rare gas matrix $^{38}$ yields a decrease of $65 \mathrm{~cm}^{-1}$ compared to free $\mathrm{CO}$. This $\mathrm{CO}$ stretch frequency decrease indicates a lengthening of the $\mathrm{CO}$ bond in the complex and a weakening of the $\mathrm{CO}$ bond as a result of the back donation from the $\mathrm{Ru} 4 \mathrm{~d}$ orbitals to the antibonding $\pi^{*}$ of $\mathrm{CO}$. and in the ferrous [Fe TPP-CO] complex $^{39,42}$.

Electronic energy levels of [Ru TPP-CO]

Table 5 : The calculated vertical excitation energies $\left(T_{v}\right.$, in $\left.\mathrm{eV}\right)$ and oscillator strength $(f)$ at minima of the singlet states of [Ru TPP-CO]. The triplet states configurations are displayed in Table 1 of the ESI.

\begin{tabular}{|c|c|c|c|c|}
\hline Transition & nature & $T_{\mathrm{v}}$ & $f$ & Exp. \\
\hline $\mathbf{S}_{0_{0}}-\mathbf{S}_{1}$ & $\pi \rightarrow \pi^{*}$ & 2.46 & 0.0004 & $2.21^{\mathrm{a}} 2.33^{\mathrm{b}}$ \\
\hline $\mathbf{S}_{0}-\mathbf{S}_{2}$ & $\pi \rightarrow \pi^{*}$ & 2.46 & 0.0002 & $2.35^{\mathrm{a}}$ \\
\hline $\mathbf{S}_{0}-\mathbf{S}_{\mathbf{3}}$ & $\mathrm{d}_{\mathrm{xy}}, \sigma(\mathrm{N}-\mathrm{C} \alpha) \rightarrow \sigma^{*}(\mathrm{Ru}-\mathrm{CO})$ & 3.09 & 0.0001 & \\
\hline $\mathrm{S}_{0}-\mathrm{S}_{4}$ & $\pi\left(\mathrm{d}_{\mathrm{xz},} \mathrm{d}_{\mathrm{yz}}-\pi_{\mathrm{CO}}^{*}\right) \rightarrow \pi^{*}$ & 3.19 & 0.0002 & \\
\hline $\mathbf{S}_{0}-\mathbf{S}_{\mathbf{5}}$ & $\pi\left(\mathrm{d}_{\mathrm{yz}}-\pi^{*} \mathrm{CO}\right) \rightarrow \sigma^{*}(\mathrm{Ru}-\mathrm{CO})$ & 3.25 & 0.1459 & \\
\hline $\mathrm{S}_{0}-\mathbf{S}_{6}$ & $\pi\left(\mathrm{d}_{\mathrm{xz}}-\pi_{\mathrm{CO}}^{*}\right) \rightarrow \sigma^{*}(\mathrm{Ru}-\mathrm{CO})$ & 3.26 & 0.1655 & \\
\hline $\mathrm{S}_{0}-\mathrm{S}_{7}$ & $\pi\left(\mathrm{d}_{\mathrm{yz}}-\pi^{*} \mathrm{CO}\right) \rightarrow \pi^{*}$ & 3.28 & 0.0136 & \\
\hline $\mathrm{S}_{0}-\mathrm{S}_{8}$ & $\pi\left(\mathrm{d}_{\mathrm{xz}}-\pi^{*} \mathrm{CO}\right) \rightarrow \pi^{*}$ & 3.37 & 0.0009 & \\
\hline $\mathrm{S}_{0}-\mathrm{S}_{9}$ & $\mathrm{~d}_{\mathrm{xy}}, \sigma(\mathrm{N}-\mathrm{C} \alpha) \rightarrow \pi^{*}$ & 3.46 & 0.0643 & \\
\hline $\mathrm{S}_{0}-\mathrm{S}_{10}$ & $\mathrm{~d}_{\mathrm{xy}}, \sigma(\mathrm{N}-\mathrm{C} \alpha) \rightarrow \pi^{*}$ & 3.46 & 0.0062 & \\
\hline $\mathrm{S}_{0}-\mathrm{S}_{11}$ & $\pi \rightarrow \pi^{*}$ & 3.55 & 1.1668 & $3.00^{\mathrm{b}}$ \\
\hline $\mathrm{S}_{0}-\mathrm{S}_{12}$ & $\pi \rightarrow \pi^{*}$ & 3.55 & 1.1394 & $3.00^{\mathrm{b}}$ \\
\hline
\end{tabular}


In Table 5, according to our calculations, the $S_{0}-S_{1}$ and $S_{0}-S_{2}$ transitions arise from $\pi-\pi *$ transitions strongly localized on the porphyrin ring. They are degenerate and can be assigned to the experimentally observed $Q$ bands of the porphyrin. The calculated excitation energy of 2.46 $\mathrm{eV}$ is in good agreement with the experimental values $(2.33$ and $2.35 \mathrm{eV}){ }^{43}$, They represent the $\mathrm{Q}_{\mathrm{x}}, \mathrm{Q}_{\mathrm{y}}$ bands degenerate in strict $\mathrm{D}_{4 \mathrm{~h}}$ symmetry about the metal, with no $\mathrm{x}$ and $\mathrm{y}$ axes dissymmetry. When the $\mathrm{Q}$ bands are degenerate, their oscillator strength is very low as calculated here for $S_{1}, S_{2}$. The $S_{11}$ and $S_{12}$ states found at $3.55 \mathrm{eV}$ represent the B (or Soret) band at 3.00 $\mathrm{eV}^{43}$. They are also degenerate for the same reason and carry all the oscillator strength.

$\mathrm{S}_{3}$ has a certain degree of porphyrin to metal charge transfer, onto the $\left.\sigma^{*}{ }_{\mathrm{Ru}-\mathrm{CO}}\right)$ antibonding orbital. $S_{3}, S_{5}$ and $S_{6}$ transitions all involve the promotion of a mainly Ru metal centered orbital towards a $\sigma^{*}(\mathrm{Ru}-\mathrm{CO})$ antibonding orbital, thus weakening the $\mathrm{Ru}-\mathrm{CO}$ bond as appears in Table 5 through the weakly bound $S_{3}, S_{5}$ and $S_{6}$ potentials. On the other hand, $S_{4}, S_{7}, S_{8}, S_{9}$ and $S_{10}$ are $\mathrm{Ru}(4 \mathrm{~d}) \rightarrow \pi^{*}$, metal to porphyrin charge transfer transitions, while $\mathrm{S}_{3}, \mathrm{~S}_{5}, \mathrm{~S}_{6}$ lead to direct excitation of the dissociative orbital $\sigma^{*}(\mathrm{Ru}-\mathrm{CO})$.

\section{Potential energy calculations on [Ru TPPCO] along the stretching Ru-CO coordinate}

For convenience in discussing the photodissociation mechanism, in the present work, when an avoided crossing was present and only in this energy domain (as for the $S_{3}-T_{m}$ crossing), we constructed locally quasidiabatic potential curves. This is achieved by fixing two points away from the avoided crossing on both the adiabatic PECs, then drawing the curve diabatically.

As shown in Figure 6, the $S_{1}, S_{2}$ (the upper states of the $Q$ band) and $S_{11}, S_{12}$ states (the upper states of the Soret transition) are bound states along the $\mathrm{Ru}-\mathrm{C}$ bond stretch reaction coordinate. All the vertical energies of the dissociative states are above the $S_{1}, S_{2}$ states, falling near the higher-lying $S_{11}, S_{12}$ states. There are eight singlet states between the $S_{1}, S_{2}$ and $S_{11}, S_{12}$ states (for simplicity, all states are not shown in Figure 6). Along the Ru-CO coordinate, the $\mathrm{S}_{1}, \mathrm{~S}_{2}$ states rise in energy and cross the quasi-repulsive $\mathrm{S}_{3}, \mathrm{~S}_{5}$ and $\mathrm{S}_{6}$ state at a Ru-C distance slightly longer than $1.9 \AA$ A. From this distance on, these states are the energetically lowest-excited singlet states of the systems. The $S_{1}$ and $S_{2}$ states are connected to the $S_{3}, S_{5}$ and $S_{6}$ states by a small energy barrier of about $0.2 \mathrm{eV}$. Then these three states cross the highest dissociative $\mathrm{T}_{\mathrm{m}}$ state at a Ru-C 
distance $\approx 2.6 \AA . \quad \mathrm{T}_{1}-\mathrm{T}_{5}$ potentials are weakly attractive as seen on Figure 6 for $\mathrm{T}_{3}-\mathrm{T}_{5} . \mathrm{T}_{1,2,3}$ correlate with the ground triplet while $\mathrm{T}_{4,5, \mathrm{~m}}$ correlate with metal excited states of dissociated [RuTPP]+CO.

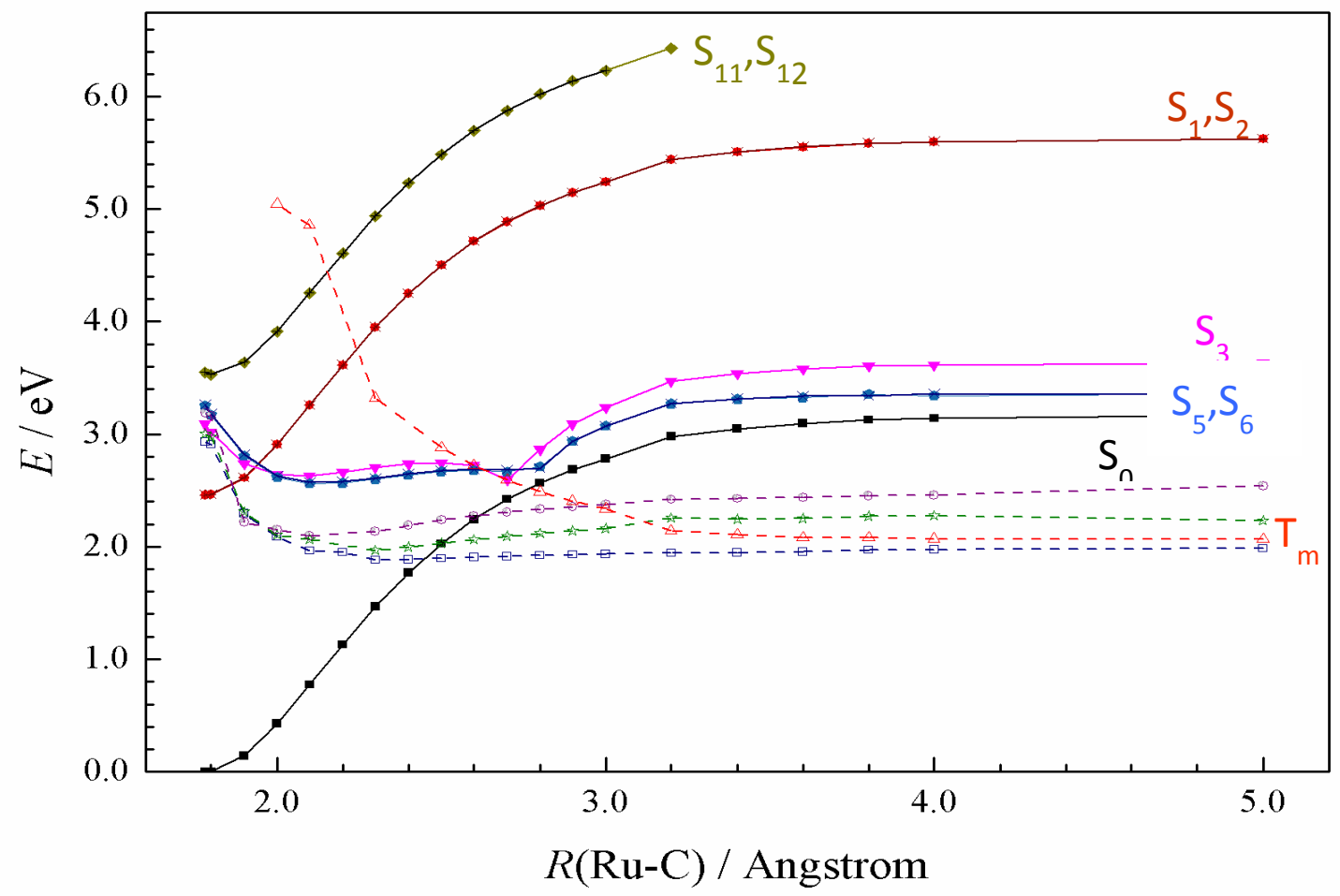

Figure 6: The TD-DFT calculated potential energy of the ground and low-lying states along the Ru-C bond dissociation coordinate. Only the $Q$ and $B$ states and the repulsive states are shown for clarity. $T_{m}$ is a high triplet state its order $m$ cannot be determined because it is too high in energy at the equilibrium geometry of [Ru TPPCO]. Singlet states are in solid lines, triplet states are dashed. $\longrightarrow \mathrm{S}_{0}, \longrightarrow \mathrm{S}_{1}, \longrightarrow \mathrm{S}_{2}, \longrightarrow \mathrm{S}_{3}, \longrightarrow \mathrm{S}_{5}, \longrightarrow \times$ $\mathrm{S}_{6}, \longrightarrow \mathrm{S}_{11}, \longrightarrow \mathrm{S}_{12},-\mathrm{T}_{3},-\mathrm{T}_{4},-\mathrm{T}_{5},-\mathrm{T}_{\mathrm{m}}, \mathrm{T}_{\mathrm{m}} . \mathrm{S}_{4}$ and $S_{7-10}$ superimpose on other curves and are not shown. $T_{1}$ and $T_{2}$ weakly attractive curves have not been displayed for clarity.

While investigating the dissociation coordinate Ru-CO it is necessary to monitor the variation of the other 'silent' coordinates., The distances between $\mathrm{Ru}$ and $\mathrm{N}, \mathrm{C} \alpha, \mathrm{C} \beta$, and Cmeso do not change when moving along the dissociative coordinate, which means that the Ru atom does not move out of the porphyrin plane and the porphyrin ring does not distort, during the dissociation. This is shown in figure 2 of the ESI 


\section{Discussion}

\section{The electronic structure of [Ru TPP] and [Ru TPP-CO]}

The electronic energy calculations on [Ru TPP-CO] allow a direct identification with good accuracy of the optically observed transitions from $S_{0}$ to $S_{1}, S_{2}$ and $S_{11} S_{12}$ (in Table 5 and Figure 6), respectively the $\mathrm{Q}_{\mathrm{x}, \mathrm{y}}$ and $\mathrm{B}$ (Soret) bands, common to metalloporphyrins. The ground electronic state of $[\mathrm{Ru} \mathrm{TPP}]$ is found unambiguously in the present calculations as a triplet with the $\mathrm{Ru}\left(\mathrm{d}_{\mathrm{xy}}\right)^{2}\left(\mathrm{~d}_{z}^{2}\right)^{2}\left(\mathrm{~d}_{\mathrm{xz}}\right)^{1}\left(\mathrm{~d}_{\mathrm{yz}}\right)^{1}$ occupancies, given the application of relativistic effects. ${ }^{45}$ Correspondingly, the [Ru TPP-CO] ground state is a singlet with $\mathrm{Ru}\left(\mathrm{d}_{\mathrm{xy}}\right)^{2}\left(\mathrm{~d}_{\mathrm{xz}}\right)^{2}\left(\mathrm{~d}_{\mathrm{yz}}\right)^{2}\left(\mathrm{~d}_{z}\right)^{2}$ occupancy. To connect both ground states of free [Ru TPP]+CO and bonded [Ru TPP-CO], intersystem crossing is required at a $\sim 2.4 \AA$ distance and as seen in Figure 6, the $\mathrm{T}_{3}, \mathrm{~T}_{5 \rightarrow} \mathrm{S}_{0}$ crossings occur almost barrierless. The singlet to triplet energy separation in free [Ru TPP] is $1.1 \mathrm{eV}$ (Figure 6). In Fe unligated porphyrins, DFT and CASPT2 calculations give also the ground electronic state as a triplet with the same configuration as above $\mathrm{e}^{46}$ and the singlet triplet separation as $1.5 \mathrm{eV}^{31}$. From calculations, the ground state of the $\mathrm{CO}$ ligated ruthenium porphyrin is, as for iron porphyrins, a singlet state, here strongly bound. Then, the dissociation energy for the neutral corresponds to the energy separation between the ${ }^{1}[\mathrm{Ru}$ TPP-CO $]$ ground state and the ${ }^{3}\left[\mathrm{Ru}^{\mathrm{II}} \mathrm{TPP}\right]+\mathrm{CO}$ asymptote and its equivalent for the ions, as shown in Figure 6 , Figure 7 and Figure 8.

\section{Dissociation dynamics of neutral [Ru TPP-CO] from the B state $\left(S_{11,12}\right)$}

The calculations along the $\mathrm{Ru}-\mathrm{CO}$ bond dissociation coordinate provide a perspective on the electronic relaxation dynamics of [Ru TPP-CO] by comparing the optically accessed potentials, i.e. Q, B and their respective curve crossings, with the time resolved experimental results.

The complex [Ru TPP-CO] excited in the Soret band $\left(\mathrm{S}_{11}, \mathrm{~S}_{12}\right)$ was observed ${ }^{47}$ to dissociate within 70 fs into $\left[\mathrm{Ru}\right.$ TPP] $+\mathrm{CO}$ and this process was assigned to a charge transfer from $\pi^{*}$ porphyrin based orbitals to a repulsive metal centered $\mathrm{Ru}-\mathrm{CO}$ orbital. It suggests the existence of a rapidly decaying intermediate which can be compared with the excited potential landscape 
along the Ru-CO coordinate. As appears in Figure 6 , the $S_{3}-S_{10}$ and $T_{3}-T_{5}$ potentials seem to collapse with that of $\mathrm{S}_{11,12}$ (B) close to $1.9 \AA$ A One can find a strong indication that the relaxation from the B state will be extremely fast. Two routes for this relaxation can be followed: i) one direct $\mathrm{S}_{11,12}(\mathrm{~B}) \rightarrow \mathrm{T}_{3}-\mathrm{T}_{5}$ at short distance, where the $\pi^{*}$ electron is transferred to a $\sigma^{*}(\mathrm{Ru}-\mathrm{CO})$ which relies on an ultrafast intersystem crossing (ISC) and such a fast crossing ( $<30 \mathrm{fs})$ was observed recently in transition metal bipyridyl complexes of $\mathrm{Fe}$ or $\mathrm{Ru}{ }^{48}$ between ${ }^{1}$ MLCT- ${ }^{3}$ MLCT charge transfer states. ii) The second path can follow the $S_{11,12}(B) \rightarrow S_{3}-S_{10}$ crossings by Internal Conversion (IC) and will lead to $\left[{ }^{3} \mathrm{Ru}\right.$ TPP $]+\mathrm{CO}$ through a second crossing (ISC) with the repulsive $\mathrm{T}_{\mathrm{m}}$ potential at $2.6 \AA$. The observed $70 \mathrm{fs}$ decay of the $\mathrm{B}$ state $\left(\mathrm{S}_{11,12}\right)$ can result from the two parallel paths. All pathways rely on ultrafast ISC, thus the numerous pathways involving all ISC and surface crossing can generate a pseudo single value decay of 70 fs, as observed ${ }^{49}$. One notes in Figure 6 that the direct decay $T_{1}-T_{3}$ channels correlate with the dissociated triplet ground state and the indirect channel $\mathrm{T}_{\mathrm{m}}$ retains less than $0.1 \mathrm{eV}$ in electronic energy. Only the direct channels $\mathrm{T}_{4}-\mathrm{T}_{5}$ dissociate to higher energies, respectively 0.4 and $0.6 \mathrm{eV}$.

\section{Ionization energies}

The determination of the ionization potentials of $[\mathrm{Ru}$ TPP-CO] and $[\mathrm{Ru}$ TPP] is rather accurate, since it appears from the SPES in Figure 4 that the ionization is vertical from the ground state geometry of the porphyrin to that of the ion, from the dominant intensity of the first peak at $6.59 \pm 0.03 \mathrm{eV}$. This provides well-defined ionization origins and agrees with small calculated structure changes upon ionization and the small differences in vertical ionization and electron affinities reported in Table 3. Aside from the large size of the porphyrin molecule, the small structural changes are in accord with the experiments ${ }^{50},{ }^{36}$ and the calculations of Liao et al. ${ }^{51}$. These calculations show that for the first-row transition metals, there is no change in charge on the metal after ionization of metallo tetraphenylporphyrins. Thus the electron is removed from the porphyrin cycle upon ionization, which explains close ionization energies for [RuTTP-CO] and [RuTTP]. In this approximation, the electronic states of [RuTTP-CO] and the [RuTTP-CO] ${ }^{+}$ ion can be classified as porphyrin doublets combined with $\mathrm{Ru}$ atom singlets or triplets: $\left[{ }^{1,3} \mathrm{Ru}\right.$ $\left.{ }^{1} \mathrm{TPP}-\mathrm{CO}\right]$ and $\left[{ }^{1,3} \mathrm{Ru}{ }^{2} \mathrm{TPP}-\mathrm{CO}\right]^{+}$. The structure of the ion will parallel that of the neutral 
regarding the metal core, with the ${ }^{2}\left[{ }^{1} \mathrm{Ru}{ }^{2} \mathrm{TPP}-\mathrm{CO}\right]^{+}$dissociating to the lowest state ${ }^{4}\left[{ }^{3} \mathrm{Ru}\right.$ $\left.{ }^{2} \mathrm{TPP}\right]^{+}+\mathrm{CO}$.

\section{Dissociation energy of the [RuTTP-CO $]^{+}$cation}

The measurement of the dissociation threshold results from a clear onset of the photodissociation yield $\mathrm{Y}$ into $[\mathrm{Ru} \mathrm{TPP}]^{+}+\mathrm{CO}$ (Figure 5) and is obtained at $\mathrm{E}_{\text {Diss }[\mathrm{Ru} \text { TPP-CO}]}{ }^{+}=8.36 \pm 0.03 \mathrm{eV}$. However, as seen in Figure 4, this onset is located in a region of the parent ion's [Ru TPP-CO ${ }^{+}$ SPES where a distinct band is manifest, attributed to an excited state of $[\mathrm{Ru} \text { TPP-CO }]^{+}$. This means that only a small part of the parent ion in this electronically excited state will fragment to $[\mathrm{Ru} \mathrm{TPP}]^{+}+\mathrm{CO}$ in this energy domain $(0<\mathrm{Y}<0.1$ Figure 5$)$. We thus surmise that the dissociation is indirect in the ion as depicted in Figure 7, as it is in the neutral (see above and Figure 6), through an initial non-adiabatic relaxation to a dissociative potential surface, of triplet symmetry. Note that the adiabatic dissociation from an excited state or a hot ground state into an excited singlet $[\mathrm{Ru} \mathrm{TPP}]^{+}+\mathrm{CO}$ would appear $\sim 1 \mathrm{eV}$ higher in energy (cf. Table 1) and give a less satisfactory agreement with theory. Then, with reference to the photodissociation of the neutral [Ru TPP-CO] in its B $\left(\mathrm{S}_{11}-\mathrm{S}_{12}\right)$ state, the dissociation of [Ru TPP-CO] ${ }^{+}$ultimately leads without barrier to a state of different multiplicity (quartet), $\left[{ }^{3} \mathrm{Ru}{ }^{2} \mathrm{TPP}\right]^{+}$. It follows that the appearance of the fragment will bear only on energetics and yield the lowest dissociation threshold as pictured in Figure 7. The fragmentation energy threshold observed corresponds to the dissociation energy of the ionic complex with $1.76 \pm 0.06 \mathrm{eV}$. 


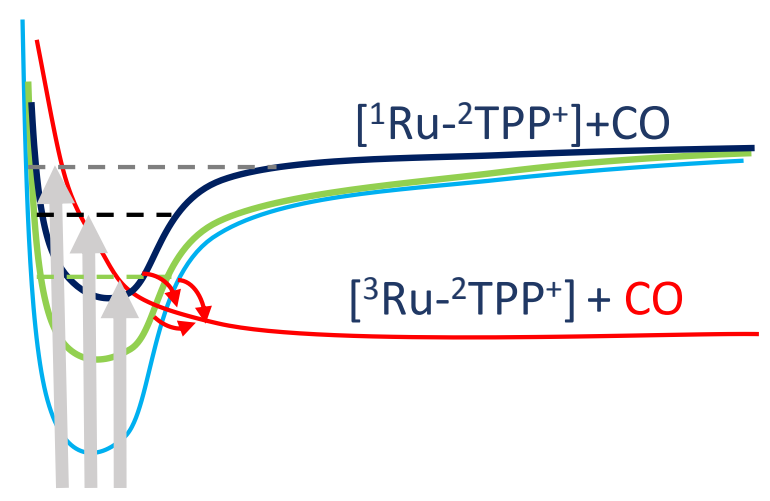

Figure 7 :Dissociation scheme in the excited states of $[\mathrm{Ru} T P P-C O]^{+}$.

\section{Experimental determination of a surprisingly high dissociation energy of [RuTTP-CO]}

Generally, the binding energy of ligands to metalloporphyrins in fifth coordination never exceeds the $1.5 \mathrm{eV}$ range, even with $\mathrm{NO}^{52}$. For example, the determination of the binding energy of $\mathrm{CO}$ in Fe porphyrins has been actively sought by DFT calculations with values ranging between $1.127^{27}$ and $0.693 \mathrm{eV}^{31,52}$ or experimentally with a value of $0.687 \pm 0.027 \mathrm{eV}^{5}$. The results are summarized in Table 6.

Table 6 : Binding energy of CO to several models complexes of free $\mathrm{Fe}^{I I}$ in gas phase or Fe porphyrins in solution

\begin{tabular}{llll}
\hline System & $\Delta \mathrm{H}(\mathrm{eV})$ & $\Delta{\mathrm{H} \mathrm{kJ} \cdot \mathrm{mole}^{-1}}$ & references \\
\hline Fe-CO & $0.9 \pm 0.3 *$ & $86.8^{*}$ & Engelking and. Lineberger ${ }^{53}$ \\
& & & \\
{$\left[\mathrm{Fe}(\text { tpps)-CO }]^{4-}\right.$} & $0.687 \pm 0.027$ & $66.3 \pm 2.6$ & Karpuschkin et al. $^{5}$ \\
Myoglobin-CO & $0.92 \pm 0.03$ & $89.5 \pm 1.3$ & Lumry et al. $^{54}$ \\
Human Hb A-CO & $0.76 \pm 0.02$ & $74.1 \pm 1.7$ & Gaud et al $^{55}$ \\
\hline
\end{tabular}

*Dissociation Energy 
Therefore, as compared to other metalloporphyrin systems, the bond energy found for [RuTPP$\mathrm{CO}$ ] appears as exceptionally large. Binding results from $\sigma$ donation (from $\mathrm{CO}$ ) into $\mathrm{d}_{\mathrm{z} 2}$ metal orbitals and $\pi$ back donation from $\mathrm{d}_{\mathrm{xz}}, \mathrm{d}_{\mathrm{yz}}$ to $\mathrm{CO} \pi *$. Back bonding is deemed to be strong for $\mathrm{Fe}-$ $\mathrm{CO}$ complexes and to contribute strongly to the observed Fe-C-O linearity.

As mentioned earlier in Table 4, the $\mathrm{CO}$ frequency in [Ru TPP-CO] is strongly decreased compared to free $\mathrm{CO}\left(199 \mathrm{~cm}^{-1}=2150-1951\right)$ by the interaction of the $\mathrm{Ru}\left(4 \mathrm{~d}_{\mathrm{xz}, \mathrm{yz}}\right)$ with the $\mathrm{CO}\left(\pi^{*}\right)$ orbitals and this decrease is stronger by $32 \mathrm{~cm}^{-1}$ in Ru-CO complexes as compared to the Fe-CO porphyrin complexes ${ }^{39,}{ }^{42}$. In turn, regarding the metal-ligand bond, Spiro et al. ${ }^{42}$ found a concomitant $18 \mathrm{~cm}^{-1}$ increase of the Ru-CO frequency relative to $\mathrm{Fe}-\mathrm{CO}$, indicating a stronger metal ligand force constant and a greater $\mathrm{Ru}-\mathrm{CO}$ bond energy. Both effects, the $\mathrm{CO}$ frequency decrease by complexation and the increase in metal- $\mathrm{CO}$ stretching frequency are correlated to $\mathrm{Ru}$ $\mathrm{d}_{\mathrm{xz}}, \mathrm{d}_{\mathrm{yz}}$ backbonding to $\mathrm{CO} \pi^{*}$.

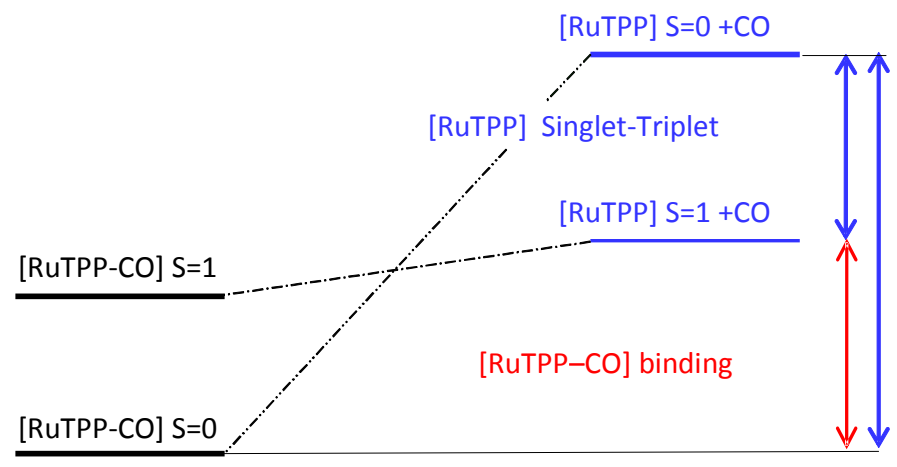

Figure 8: Scheme of the binding energy of [RuTPP CO] showing its dependence on the Singlet-Triplet energy separation of uncomplexed [RuTPP] species owing to spin-crossover.

All correlations point to a stronger $\mathrm{Ru}-\mathrm{CO}$ bond than Fe-CO. However the relative decrease of the $\mathrm{CO}$ frequency for Ru-CO $\left(-32 \mathrm{~cm}^{-1}\right.$ compared to $\left.\mathrm{Fe}-\mathrm{CO}\right)$ is not so important relative to the 
$199 \mathrm{~cm}^{-1}$ decrease in CO frequency by complexation to Ru and the twofold increase in Ru-CO energy. In addition, the calculated Ru-CO bond length is $1.791 \AA$, the experimentally-determined distance $1.82 \AA$, slightly longer by $\sim 0.02-0.05 \AA$ than the corresponding calculated $\mathrm{Fe}-\mathrm{CO}$ bond $1.77 \AA^{52}$. Orbital effects are indeed clear as shown by a stronger backbonding for Ru-CO complexes compared to Fe-CO bonding. However they cannot account solely for the increased binding energy of [Ru TPP]-CO compared to [Fe TPP]-CO. The binding energy depends also on the triplet and singlet states separation in uncomplexed [Ru TPP] due to the spin crossing necessary for binding (see Figure 8). Indeed, the singlet triplet energy difference in iron porphyrins is higher $(1.5 \mathrm{eV})^{31}$ than that of the ruthenium found here $(1.1 \mathrm{eV})$ and by Matsusawa $(0.9 \mathrm{eV})^{30}$. Therefore the above binding energy in [Ru TPP-CO] would already decrease by $0.4 \mathrm{eV}$ with all potentials considered identical and the spin splitting of [Fe TPP-CO]. A similar but extreme situation has been found for the Fe Porphyrin-NO complex, where the complexed system has a high force constant for the metal -ligand bond but a small well depth, resulting from energy loss in binding due to spin cross over. ${ }^{56}$

\section{Conclusions}

A combined theoretical and experimental investigation of the structure and electronic states of [Ru $\left.{ }^{\mathrm{II}} \mathrm{TPP}-\mathrm{CO}\right]$, has allowed the characterization of a strikingly strong $\mathrm{Ru}$ II $-\mathrm{CO}$ ligation energy, as compared with analogous $\mathrm{Fe}^{\mathrm{II}}$ porphyrin systems. Measurements of the adiabatic ionization energies of [Ru TPP] and [Ru TPP-CO] and of the ion dissociation threshold of [Ru TPP-CO] ${ }^{+}$ were made with VUV synchrotron radiation. Using a Born-Haber cycle has allowed the determination of the dissociation energies of the neutral and ionic complexes, $\mathrm{E}_{\text {[Ru TPP-CO] }}$ $=1.88 \pm 0.06 \mathrm{eV}$ and $\mathrm{E}_{[\mathrm{Ru} \text { TPP-CO }]_{+}}=1.76 \pm 0.06 \mathrm{eV}$. Extensive quantum calculations with Density Functional Theory have shown a full accord with these measurements in terms of ionization, bond energies and dissociation dynamics. [ $\left.\mathrm{Ru}^{\mathrm{II}} \mathrm{TPP}-\mathrm{CO}\right]$ is more strongly bound than [Fe ${ }^{\mathrm{II}} \mathrm{TPP}-$ $\mathrm{CO}$. However, the increase in binding energy for the ruthenium case is only partly due to an increased strength of the metal ligand bond due to a stronger $\mathrm{Ru} 4 \mathrm{~d}_{\mathrm{xz}, \mathrm{yz}} \rightarrow \pi^{*} \mathrm{CO}$ backbonding. The smaller splitting $\mathrm{E}_{[\mathrm{Ru} \text { TPP] }}{ }^{1}-\mathrm{E}_{[\mathrm{Ru} \text { TPP] }}{ }^{3}$ with respect to the Fe complex by $\sim 0.4 \mathrm{eV}$ plays equally a crucial role. Therefore, the electronic structure properties of ruthenium-CO complexes are 
amenable to valuable comparisons with their iron equivalents relative to the electron distribution over the metal and ligand orbitals and the resulting ligand binding propensities. These comparisons are more direct than that of their thermodynamical binding energies.

\section{Acknowledgements}

We are indebted to the general technical staff of Synchrotron Soleil for running the facility under proposals \#20140316 and \#20130190. We would like also to thank Jean-François Gil and Xiaofeng Tang for their technical help on the SAPHIRS molecular beam chamber. We acknowledge the financial support of the French initiative, Labex PALM for the project PHOTOHEME, which supported the junior chair of Shufen Chen in 2013-2015.

\section{References}

1. J. N. Harvey, J. Am. Chem. Soc., 2000, 122, 12401.

2. $\quad$ K. S. Suslick and T. J. Reinert, J. Chem. Educ., 1985, 62, 974.

3. L. Ferrand, S. Soorkia, G. Gregoire, M. Broquier, B. Soep and N. Shafizadeh, PCCP, 2015, 17, 25693.

4. C. Slebodnick, W. K. Seok, K. Kim and J. A. Ibers, Inorg. Chim. Acta, 1996, 243, 57.

5. T. Karpuschkin, M. M. Kappes and O. Hampe, Angew. Chem. Int. Ed., 2013, 52, 10374.

6. Born-Haber Cycle, http://en.wikipedia.org/wiki/Born\%E2\%80\%93Haber_cycle.

7. M. Richard-Viard, A. Delboulbé and M. Vervloet, Chem. Phys., 1996, 209, 159.

8. T. Xiaofeng, G. A. Garcia, J.-F. Gil and L. Nahon, Rev. Sci. Instrum., 2015, 86, 1.

9. G. A. Garcia, B. K. Cunha de Miranda, M. Tia, S. Daly and L. Nahon, Rev. Sci. Instrum., 2013, 84, 053112.

10. L. Nahon, N. de Oliveira, G. A. Garcia, J. F. Gil, B. Pilette, O. Marcouille, B. Lagarde and F. Polack, Journal of Synchrotron Radiation, 2012, 19, 508.

11. B. Mercier, M. Compin, C. Prevost, G. Bellec, R. Thissen, O. Dutuit and L. Nahon, Journal of Vacuum Science \& Technology A: Vacuum, Surfaces, and Films, 2000, 18, 2533. 
12. A. T. J. B. Eppink and D. H. Parker, Rev. Sci. Instrum., 1997, 68, 3477.

13. G. A. Garcia, L. Nahon and I. Powis, Rev. Sci. Instrum., 2004, 75, 4989.

14. J. C. Poully, J. P. Schermann, N. Nieuwjaer, F. Lecomte, G. Gregoire, C. Desfrancois, G. A. Garcia, L. Nahon, D. Nandi, L. Poisson and M. Hochlaf, PCCP, 2010, 12, 3566.

15. Y. Majdi, M. Hochlaf, Y. Pan, K.-C. Lau, L. Poisson, G. A. Garcia, L. Nahon, M. M. AlMogren and M. Schwell, J. Phys. Chem. A., 2015, 119, 5951.

16. M. Briant, L. Poisson, M. Hochlaf, P. de Pujo, M.-A. Gaveau and B. Soep, Phys. Rev. Lett., 2012, 109, 193401.

17. M. E. Casida, in Recent Advances in Density Functional Methods, ed. C. Delano P Chong (University of British Columbia, World Scientific, Singapore, 1996, vol. 1.

18. M. J. Frisch, G. W. Trucks, H. B. Schlegel, G. E. Scuseria, M. A. Robb, J. R. Cheeseman, G. Scalmani, V. Barone, B. Mennucci, G. A. Petersson, H. Nakatsuji, M. Caricato, X. Li, H. P. Hratchian, A. F. Izmaylov, J. Bloino, G. Zheng, J. L. Sonnenberg, M. Hada, M. Ehara, K. Toyota, R. Fukuda, J. Hasegawa, M. Ishida, T. Nakajima, Y. Honda, O. Kitao, H. Nakai, T. Vreven, J. A. Montgomery Jr., J. E. Peralta, F. Ogliaro, M. J. Bearpark, J. Heyd, E. N. Brothers, K. N. Kudin, V. N. Staroverov, R. Kobayashi, J. Normand, K. Raghavachari, A. P. Rendell, J. C. Burant, S. S. Iyengar, J. Tomasi, M. Cossi, N. Rega, N. J. Millam, M. Klene, J. E. Knox, J. B. Cross, V. Bakken, C. Adamo, J. Jaramillo, R. Gomperts, R. E. Stratmann, O. Yazyev, A. J. Austin, R. Cammi, C. Pomelli, J. W. Ochterski, R. L. Martin, K. Morokuma, V. G. Zakrzewski, G. A. Voth, P. Salvador, J. J. Dannenberg, S. Dapprich, A. D. Daniels, Ö. Farkas, J. B. Foresman, J. V. Ortiz, J. Cioslowski and D. J. Fox, Gaussian, Inc., Wallingford, CT, USA, 2009.

19. R. Krishnan, J. S. Binkley, R. Seeger and J. A. Pople, J. Chem. Phys., 1980, 72, 650.

20. D. Andrae, U. Haussermann, M. Dolg, H. Stoll and H. Preuss, Theor. Chim. Acta, 1990, $77,123$.

21. A. D. Becke, J. Chem. Phys., 1993, 98, 5648.

22. Y. Zhao and D. G. Truhlar, J. Chem. Phys., 2006, 125, 194101.

23. Y. Zhao and D. G. Truhlar, Acc. Chem. Res., 2008, 41, 157.

24. R. Peverati and D. G. Truhlar, J. Phys. Chem. Lett., 2011, 2, 2810.

25. A. Ishikawa and S. Sakaki, J. Phys. Chem. A., 2011, 115, 4774.

26. J. P. Collman, C. E. Barnes, P. N. Swepston and J. A. Ibers, J. Am. Chem. Soc., 1984, 106,3500 .

27. B. D. Dunietz, A. Dreuw and M. Head-Gordon, J.Phys.Chem. B, 2003, 107, 5623. 
28. T. Yanai, D. P. Tew and N. C. Handy, Chem. Phys. Lett., 2004, 393, 51.

29. B. Delley, Physica B: Condensed Matter, 1991, 172, 185.

30. N. Matsuzawa, M. Ata and D. A. Dixon, J. Phys. Chem., 1995, 99, 7698.

31. M. Radoń and K. Pierloot, J. Phys. Chem. A., 2008, 112, 11824.

32. S. V. Lindeman, S. V. Rosokha, D. Sun and J. K. Kochi, J. Am. Chem. Soc., 2002, 124, 843.

33. C. Narth, N. Gillet, B. Levy, I. Demachy and A. de la Lande, Can J Chem, 2013, 91, 628.

34. A. Ghosh, J. Am. Chem. Soc., 1995, 117, 4691.

35. N. E. Gruhn, D. L. Lichtenberger, H. Ogura and F. A. Walker, Inorg. Chem., 1999, 38, 4023.

36. P. Dupuis, R. Roberge and C. Sandorfy, Chem. Phys. Lett., 1980, 75, 434.

37. L. Krim, S. Sorgues, B. Soep and N. Shafizadeh, J. Phys. Chem. A, 2005, 109, 8268.

38. M. F. Zhou and L. Andrews, J. Phys. Chem. A, 1999, 103, 6956.

39. J. R. Hill, C. J. Ziegler, K. S. Suslick, D. D. Dlott, C. W. Rella and M. D. Fayer, J. Phys. Chem., 1996, 100, 18023.

40. H. Dubost, Chem. Phys., 1976, 12, 139.

41. M. P. Andersson and P. Uvdal, J. Phys. Chem. A, 2005, 109, 2937.

42. D. Kim, Y. O. Su and T. G. Spiro, Inorg. Chem., 1986, 25, 3993.

43. I. Iwakura, T. Kobayashi and A. Yabushita, Inorg. Chem., 2009, 48, 3523.

44. M. W. Mara, M. Shelby, A. Stickrath, M. Harpham, J. Huang, X. Zhang, B. M. Hoffman and L. X. Chen, J.Phys.Chem. B, 2013, 117, 14089.

45. M.-S. Liao and S. Scheiner, Chem. Phys., 2002, 285, 195.

46. M. S. Liao and S. Scheiner, J. Chem. Phys., 2002, 116, 3635.

47. S. Sorgues, L. Poisson, K. Raffael, L. Krim, B. Soep and N. Shafizadeh, J. Chem. Phys., 2006, 124, 114302.

48. M. Chergui, Acc. Chem. Res., 2015, 48, 801.

49. N. Shafizadeh, L. Krim, S. Sorgues and B. Soep, Chem. Phys. Lett., 2002, 357, 37. 
50. S. C. Khandelwal and J. L. Roebber, Chem. Phys. Lett., 1975, 34, 355.

51. L. Meng Sheng and S. Scheiner, J. Chem. Phys., 2002, 117, 205.

52. C. Rovira, K. Kunc, J. Hutter, P. Ballone and M. Parrinello, J. Phys. Chem. A, 1997, 101, 8914.

53. P. C. Engelking and W. C. Lineberger, J. Am. Chem. Soc., 1979, 101, 5569.

54. R. Lumry, M. H. Keyes and M. Falley, J. Am. Chem. Soc., 1971, 93, 2035.

55. H. T. Gaud, B. G. Barisas and S. J. Gill, Biochem. Biophys. Res. Commun., 1974, 59, 1389.

56. V. K. K. Praneeth, F. Paulat, T. C. Berto, S. D. George, C. Näther, C. D. Sulok and N. Lehnert, J. Am. Chem. Soc., 2008, 130, 15288. 